\title{
Mechanical and Environmental Factors in the Cyclic and Static Fatigue of Silicon Nitride
}

\author{
David S. Jacobs ${ }^{\star}$ and I-Wei Chen* \\ Department of Materials Science and Engineering, University of Michigan, \\ Ann Arbor, Michigan 48109-2136
}

\begin{abstract}
The effects of environment on cyclic and static fatigue behavior were investigated with hot-pressed silicon nitride materials. Tests were conducted at ambient temperature on standard compact tension specimens, and a dc electric potential technique was used to monitor crack lengths in situ. The results indicate that the environmental sensitivity of our materials under both cyclic and static loading mirrors that of durable glasses in static fatigue. The materials were most sensitive to water in the environment, while changes in pH had no significant effect in the range tested. In addition, $\mathrm{NH}_{3}$ was much less reactive with our materials than with vitreous $\mathrm{SiO}_{2}$. In some cases, the intergranular glass appears to be the site of environmental interaction. Evidence was also found that cyclic fatigue is not simply a manifestation of static fatigue. Cyclic fatigue was seen to occur in the absence of measurable static fatigue, and the data indicate that the mechanism of cyclic fatigue involves damage to the crack wake shielding zone.
\end{abstract}

\section{Introduction}

C RACK growth in ceramic materials occurs under both static and cyclic fatigue conditions. Static fatigue proceeds by subcritical crack growth under constant loads and has been recognized to be an environmentally activated process. Cyclic fatigue, on the other hand, is classically thought of as a mechanical phenomenon in which load oscillation leads to crack propagation. Both types of fatigue have been observed in $\mathrm{ZrO}_{2}{ }^{1-5}$ $\mathrm{Al}_{2} \mathrm{O}_{3}{ }^{6,7} \mathrm{Si}_{3} \mathrm{~N}_{4},{ }^{8-15} \mathrm{SiC} / \mathrm{Al}_{2} \mathrm{O}_{3}$ composites, ${ }^{16}$ and in several other ceramic materials and composites. Crack growth in cyclic fatigue is usually several orders of magnitude faster than in static fatigue at the same maximum applied stress intensity, $K_{\text {max }}$. In addition, some environmental sensitivity of cyclic fatigue was noted in several studies of $\beta-\mathrm{Si}_{3} \mathrm{~N}_{4}{ }^{8-15}$ but was not extensively investigated.

Cyclic fatigue in ceramics has been found to differ in several ways from fatigue in more ductile materials. Ceramics do not exhibit the fatigue striations seen in ductile materials, and the difference in appearance of fatigue fractures and fast fractures, while distinguishable under careful comparison, is often too small to quantify. ${ }^{3,16}$ Ceramics have also been shown to be much more sensitive to stress intensity than metals or polymers, as quantified through the Paris law:

$$
\mathrm{d} a / \mathrm{d} N=A(\Delta K)^{n}
$$

Here $\mathrm{d} a / \mathrm{d} N$ is the crack growth rate in $\mathrm{m} /$ cycle, $\Delta K$ is the difference between the maximum and minimum applied stress intensity, $K_{\max }$ and $K_{\min }, n$ is an exponent, and $A$ is a constant

K. Jakus-contributing editor

\footnotetext{
Manuscript No. 194078. Received November 1, 1993; approved December 15 , 1993.

Supported by the Air Force Office of Scientific Research under Grant No. 91-0094. *Member, American Ceramic Society.
}

which depends on the $R$-ratio ( $K_{\min } / K_{\max }$ ). A typical $n$ value may range from 8 to 120 for ceramics in cyclic fatigue, ${ }^{1-16}$ compared to typical values of 2 to 5 for metals and polymers. Recent evidence $^{3}$ suggests that the large $n$ values found for ceramics really arise from a strong dependence on $K_{\max }$ and only a relatively weak, quadratic dependence of $\Delta K$. The above features are thought to be inherent to all brittle materials. ${ }^{3,16}$

The literature shows that $\mathrm{Si}_{3} \mathrm{~N}_{4}$ ceramics display the same basic features in cyclic fatigue as described above. ${ }^{8-15}$ This includes a growth rate enhancement by cyclic loading relative to static loading by up to 3 orders of magnitude, an environmental sensitivity, lack of fatigue striations, and a strong dependence on $K_{\max }$ with a weaker dependence on $\Delta K$. Evidence has also been found in $\mathrm{Si}_{3} \mathrm{~N}_{4}$ for true cyclic fatigue in the absence of measurable static fatigue. ${ }^{15}$ Other features typical of fatigue in ceramic materials have also been observed in $\mathrm{Si}_{3} \mathrm{~N}_{4}$. Increasing the $R$-ratio tends to decrease crack growth rates for a given $K_{\text {max }}$. However, at high growth rates $\left(\approx 10^{-5} \mathrm{~m} / \mathrm{s}\right)$ this effect becomes small. Test frequency has no significant effect on crack growth rates (expressed as $\mathrm{m} /$ cycle) as long as the $K_{\max }$ in cyclic fatigue is lower than the threshold $K$ for static fatigue $\left(K_{\text {th,s }}\right)$. Kishimoto et $a l^{10-12}$ found that crack velocities below $K_{\mathrm{th}, \mathrm{s}}$ were cycledependent only, indicating a purely mechanical effect, while above $K_{\mathrm{th}, \mathrm{s}}$ velocities became more time-dependent, indicating a contribution from static fatigue. Other studies of $\mathrm{Si}_{3} \mathrm{~N}_{4}{ }^{8.15}$ have shown that cyclic fatigue growth rates in an inert environment (vacuum) may be up to 3 orders of magnitude slower than those in moist air. These observations of cyclic fatigue in $\mathrm{Si}_{3} \mathrm{~N}_{4}$ are reminiscent of cyclic stress corrosion cracking seen in metals, in which environmental interactions at the strained crack tip play an important role in controlling crack growth rates. ${ }^{10}$

Some investigators have speculated that the environmental sensitivity observed for $\mathrm{Si}_{3} \mathrm{~N}_{4}$ is linked to the intergranular glass phase present in these materials (usually an $\mathrm{Si}-\mathrm{O}-\mathrm{N}$ based glass). ${ }^{10-15}$ For $\mathrm{SiO}_{2}$-based glasses under static fatigue, Wiederhorn et al.$^{17,18}$ and Freiman ${ }^{19-21}$ have established that even a few ppm of water in the test environment can have a dramatic effect on crack growth rates. Studies by Simmons and Freiman ${ }^{24}$ have established that static fatigue in glasses can also be sensitive to $\mathrm{pH}$ and glass composition. Michalske et al..$^{22.23}$ have found that other chemical species, such as $\mathrm{NH}_{3}$, also affect growth rates, and they have devised a model for static fatigue in ionic solids based on the chemisorption of reactive species onto strained crack-tip bonds. Finally, Wiederhorn et al. ${ }^{25}$ have observed static fatigue under vacuum for a variety of glasses at room temperature and above. Thus, at least for glasses, static fatigue is an intrinsic, thermally activated mechanical phenomenon which is enhanced by environment. Whether similar behaviors exist in $\mathrm{Si}_{3} \mathrm{~N}_{4}$ materials under cyclic fatigue loading has not been extensively investigated.

In light of the above observations, an investigation into the complex relationships between environment, cyclic fatigue, and static fatigue has been undertaken in this study. The explicit effects of several test environments on both cyclic and static fatigue have been determined and the role of the intergranular glass phase investigated. In addition, strong evidence is found 
Table I. Compositions of $\boldsymbol{\beta}-\mathrm{Si}_{\mathbf{3}} \mathbf{N}_{4}$ Materials

\begin{tabular}{ccc}
\hline & \multicolumn{2}{c}{ Composition (wt\%) } \\
\cline { 2 - 3 } & \multicolumn{1}{c}{$\mathrm{SN1}$} & $\mathrm{SN} 2-4$ \\
\hline$\alpha-\mathrm{Si}_{3} \mathrm{~N}_{4}{ }^{*}$ & 90.00 & 90.51 \\
$\mathrm{Al}_{2} \mathrm{O}^{+}$ & 6.25 & 1.45 \\
$\mathrm{AlN}^{+}$ & 0 & 2.31 \\
$\mathrm{Y}_{2} \mathrm{O}_{3}{ }^{8}$ & 3.75 & 5.74 \\
\hline *UBE E-10. ${ }^{+}$ALCOA. & ${ }^{*}$ Stark. ${ }^{8}$ Aldrich.
\end{tabular}

that cyclic fatigue, unlike static fatigue, causes damage to crack wake shielding, and that this mechanism alone is sufficient to propagate a crack in our materials. Thus cyclic fatigue is seen to be a mechanical process that may be enhanced by interactions with the environment.

\section{Experimental Procedure}

\section{(1) Materials}

Test specimens were hot-pressed from $\alpha$-silicon nitride powders containing $\mathrm{Y}_{2} \mathrm{O}_{3}, \mathrm{Al}_{2} \mathrm{O}_{3}$, and $\mathrm{AlN}$ as sintering aids. Before hot pressing, the starting powders were attrition milled for $2 \mathrm{~h}$ in 2-propanol containing $0.50 \mathrm{wt} \%$ of a surfactant (DOW XUS 40303.00). Four materials were tested, designated SN1-4. The starting powder compositions are given in Table I, and characteristic material properties are given in Table II. The variations in toughness of SN2-4 were produced by altering the hot-pressing conditions slightly. Note that the $K_{\mathrm{IC}}$ values listed in Table II were found to be different in water-rich and water-poor environments. X-ray diffraction analysis revealed that the major crystalline phase was $\beta-\mathrm{Si}_{3} \mathrm{~N}_{4}$ for all materials. A small amount of residual $\alpha-\mathrm{Si}_{3} \mathrm{~N}_{4}$ was also present, but crystalline $\mathrm{Y}_{3} \mathrm{Al}_{5} \mathrm{O}_{12}$ (YAG) was not found. From the literature it is expected that an oxynitride glass is present as an intergranular phase. ${ }^{26}$

\section{(2) Mechanical Testing}

Compact tension (CT) specimens were fabricated in accordance with ASTM E 647-83, with $W=25.4 \mathrm{~mm}$ and $B=4.00$ $\mathrm{mm}$. The specimens were machined with a half-chevron notch and were precracked in tension-tension cyclic loading until a sharp crack was grown at least $2 \mathrm{~mm}$ beyond the notch root. Crack lengths were measured in situ using a dc electric potential technique. For this purpose, a continuous $\mathrm{Ni}$ or Ti film about $0.1 \mu \mathrm{m}$ thick was deposited on one highly polished face of the CT specimen. The adhesion of the film to the specimen was strong in all cases, and the film was observed to fracture brittlely along with the specimen. Use of a high-resolution digital multimeter enabled us to resolve changes in crack length of less than $2 \mu \mathrm{m}$.

Fatigue tests were carried out using an MTS servo-hydraulic test machine. Tests were conducted in load control using a closed-loop computer system. Three loading schedules were used. The first involved only cyclic loading using a sinusoidal waveform with a frequency between 1 and $5 \mathrm{~Hz}$ and a load ratio $\left(K_{\min /} K_{\max }\right)$ of $R=0.1$. The second involved only static loading using a constant applied load. In both of these loading schedules, the crack length, and thus $K_{\max }$, were allowed to increase in order to cover a wide range of $K$ and crack velocity. Before performing static loading tests, the crack was usually propagated a short distance at low $K_{\max }$ (low $\mathrm{d} a / \mathrm{d} t$ and a large number of cycles) to try to minimize load history effects. In some cases, quasi-static loading was performed at the beginning of the static fatigue test. This was often necessary to offset a tendency for

Table II. Mechanical Properties of $\beta-\mathrm{Si}_{3} \mathrm{~N}_{4}$ Materials

\begin{tabular}{lllll}
\hline & SN1 & SN2 & SN3 & SN4 \\
\hline Young's modulus (GPa) & 286 & 300 & 300 & 305 \\
$K_{\text {IC }}$ in $\mathrm{H}_{2} \mathrm{O}\left(\mathrm{MPa} \cdot \mathrm{m}^{1 / 2}\right)$ & 4.03 & 5.10 & 5.60 & 5.25 \\
$K_{\text {IC }}$ in oil $\left(\mathrm{MPa} \cdot \mathrm{m}^{1 / 2}\right)$ & 4.35 & 5.41 & 5.85 & 5.65 \\
\hline
\end{tabular}

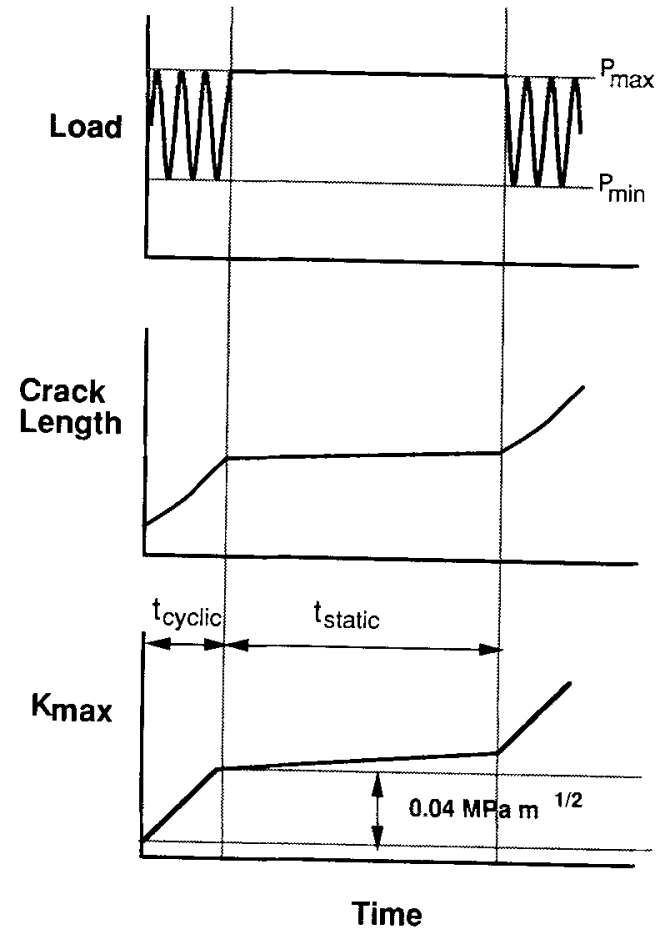

Fig. 1. Details of block loading test: $t_{\text {static }}=2 \mathrm{~h} ; t_{\text {cyclic }}$ is the time required for $K_{\max }$ to increase by $0.04 \mathrm{MPa} \cdot \mathrm{m}^{1 / 2}$ during cyclic fatigue and is not uniquely specified.

crack arrest at very low $K_{\max }$ and to shorten the duration of the test. In these cases, the load was stepped up about $2 \mathrm{~N}$ every 30 to $60 \mathrm{~min}$ until a $\mathrm{d} a / \mathrm{d} t$ of about $1 \times 10^{-9} \mathrm{~m} / \mathrm{s}$ was recorded, after which the load was left constant. The third loading schedule is referred to herein as block loading. During this type of test, cyclic and static loading were alternated many times to examine any synergism between cyclic and static fatigue at different $K_{\max }$ values. The specific details of this loading sequence are given in Fig. 1.

\section{(3) Environments}

Fatigue tests were conducted in the seven test environments listed in Table III. All tests except those in moist air were performed inside an environment chamber. An alkaline environment was used to sample the effect of $\mathrm{pH}$ since it was expected to be more corrosive than an acidic environment for our materials and thus to show any pH effect more clearly. ${ }^{27}$ Extremes of $\mathrm{pH}$ were avoided due to the hazards involved. Table IV shows the test environments in which data were collected for the materials used in this study. Cyclic fatigue data were collected in moist air for all four materials, and this was used as a "reference" environment to allow comparison of data from the different specimens.

\section{(4) Microscopy}

After specimen failure, fracture surfaces were observed under a scanning electron microscope (SEM: Hitachi S-800). Each field of view was correlated with the type of loading and

Table III. Test Environments

\begin{tabular}{ll}
\hline Environment & \multicolumn{1}{c}{ Description } \\
\hline Moist air & Relative humidity $=35-65 \%$ \\
$\mathrm{H}_{2} \mathrm{O}$ & Deionized and double distilled, $\mathrm{pH} \approx 4.5$ \\
$\mathrm{NaOH}_{(a q)}$ & $0.001 M$ solution, $\mathrm{pH} 11.0$ \\
$\mathrm{Decane}$ & Liquid, water saturated \\
$\mathrm{NH}_{3(g)}$ & Anhydrous grade, flowing \\
$\mathrm{N}_{2(g)}$ & $99.998 \%$ pure \\
$\mathrm{Vacuum}$ & $P=4 \times 10^{-4}$ torr \\
\hline
\end{tabular}


Table IV. Environments Used for Fatigue Testing of Each Specimen

\begin{tabular}{|c|c|c|c|c|c|c|c|c|}
\hline & \multicolumn{4}{|c|}{ Cyclic } & \multicolumn{4}{|c|}{ Static } \\
\hline & SN1 & $\mathrm{SN} 2$ & $\mathrm{SN} 3$ & SN4 & SNI & $\mathrm{SN} 2$ & SN3 & SN4 \\
\hline $\begin{array}{l}\text { Moist air } \\
\mathrm{DI} \mathrm{H}_{2} \mathrm{O} \\
\mathrm{NaOH}_{(a q)} \\
\text { Decane } \\
\mathrm{NH}_{3(g)} \\
\mathrm{N}_{2(g)} \\
\text { Vacuum }\end{array}$ & $\stackrel{+}{\oplus}$ & $\begin{array}{l}+ \\
+\end{array}$ & $\oplus$ & $\begin{array}{l}\oplus \\
\ominus \\
\oplus\end{array}$ & $\oplus$ & $\underset{\oplus}{\oplus}$ & & $\oplus$ \\
\hline
\end{tabular}

environment that produced that part of the fracture surface. In addition, a rectangular bar was cut from each specimen, notched with a diamond wafering blade, and fast fractured. The fracture surfaces so produced were observed in the SEM. They were then etched in molten $\mathrm{NaOH}$ to remove the intergranular glass phase and photographed again in the SEM. These observations helped to distinguish the grain boundary glass from the $\mathrm{Si}_{3} \mathrm{~N}_{4}$ grains in the fracture surfaces resulting from cyclic and static loading.

\section{Results}

\section{(1) Normalization of Data}

Figure 2(a) shows cyclic fatigue curves obtained in the reference environment (moist air) for all four materials. The data are plotted in accordance with Eq. (1), but since $\Delta K=K_{\max }(1-$ $R$ ) and $R=0.1$ for all tests, $K_{\max }$ is used rather than $\Delta K$. This allows direct comparison of cyclic and static fatigue data. The slopes of these curves are approximately the same, but their position along the abscissa is in order, from left to right, of increasing $K_{\mathrm{IC}}$ (cf. Table II). (On the other hand, the position and slope of the fatigue curve for a given material in a given environment were highly reproducible.)

To allow meaningful comparison of test results for various toughness materials, many authors suggest using $K_{\mathrm{IC}}$ to normalize cyclic and static fatigue data. ${ }^{28-30}$ Indeed, Dauskardt et al. ${ }^{29}$ have shown that normalizing by the plateau toughness from $R$-curve measurements produced a "universal" cyclic fatigue curve for several Mg-PSZ materials having very different microstructures and toughnesses. Since $K_{\mathrm{IC}}$ (and presumably the $R$-curve) varies with environment (see Table II), normalizing parameters were selected by constructing a "universal" fatigue curve from cyclic fatigue data in a reference environment (moist air), in accordance with the results of Dauskardt et al. First, the data for the SN3 material were normalized by setting $K_{\text {norm }}=K_{\max } / N_{3}$, where the shift parameter $N_{3}$ was arbitrarily chosen as the $K_{\mathrm{IC}}$ found by Vickers indentation in $\mathrm{H}_{2} \mathrm{O}$. The other three curves were then graphically shifted to give the best superposition with the SN3 curve. This "universal" curve, along with the shift parameters, $N_{i}$, are shown in Fig. 2(b). Note that the $N_{i}$ are the same, within experimental error, as the $K_{\mathrm{IC}}$ values listed in Table II for Vickers indentation in water. These $N_{i}$ were then used to normalize data obtained in other environments for each material.

We expect that the above procedure will produce a set of "universal" curves, one for each test environment, showing the trend of environmental interaction for this general class of material $\left(\mathrm{Si}_{3} \mathrm{~N}_{4}\right.$ with a Y-Si-Al-O-N intergranular glass of a given composition). This, as we shall see, also includes the SN 1 material, which has a slightly different glass composition than the others. Since the normalization procedure was initially established from cyclic fatigue data, it is possible that the static fatigue data do not normalize the same way. Later we will show that, indeed, static fatigue data for the SN1 material normalizes differently from the others, and that this is related to the $R$-curves of our materials.

The normalized cyclic fatigue data are plotted in Fig. 3, and the static fatigue data in Fig. 4. Data from all four materials are represented in these figures, but only those entries in Table IV marked by a " $\oplus$ " are shown for the sake of clarity. Uncharacteristically high and low $\mathrm{d} a / \mathrm{d} t$ values have also been eliminated to reduce the scatter in the data and to show the trends more clearly. The trends seen in Figs. 3 and 4 are summarized below.

\section{(2) Cyclic Fatigue}

(A) Moist Environments: Figure 3(a) shows cyclic fatigue data acquired in environments containing a significant amount of $\mathrm{H}_{2} \mathrm{O}$. Decane is included in this set since it is expected to have absorbed water by contact with ambient air. ${ }^{19}$ Cyclic fatigue proceeded fastest in these four environments (compared to the "dry" environments shown in Fig. 3(b)), but

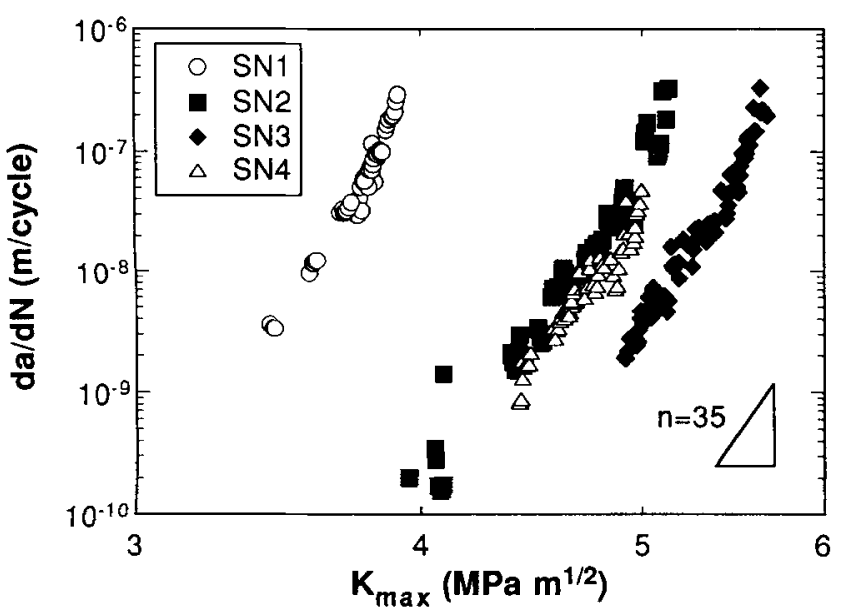

(a)

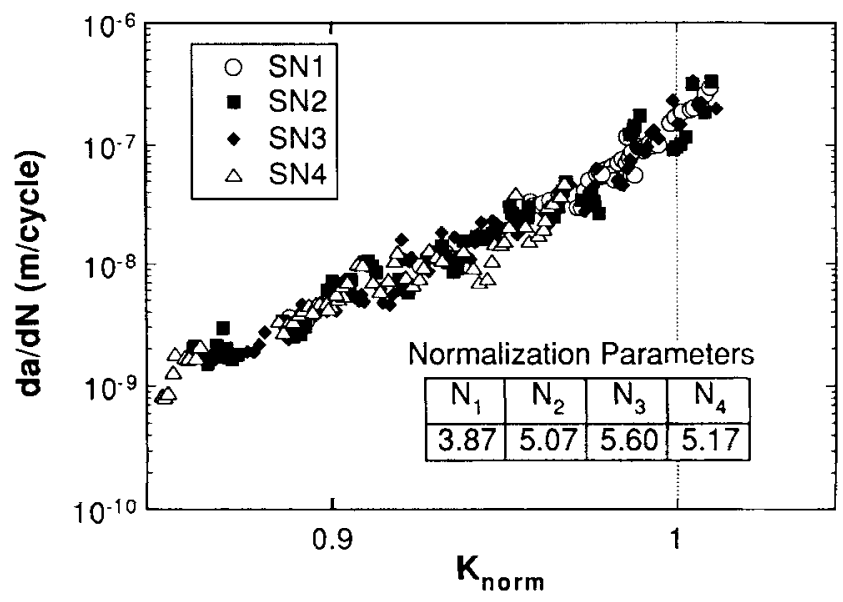

(b)

Fig. 2. (a) Variation of cyclic fatigue behavior in moist air environment for all four $\mathrm{Si}_{3} \mathrm{~N}_{4}$ materials. (b) Data normalized so curves coincide. 


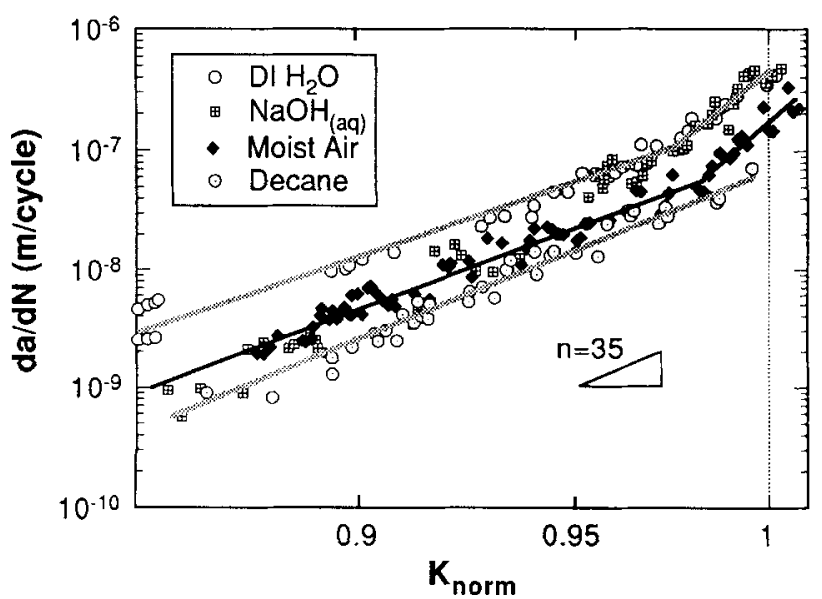

(a)

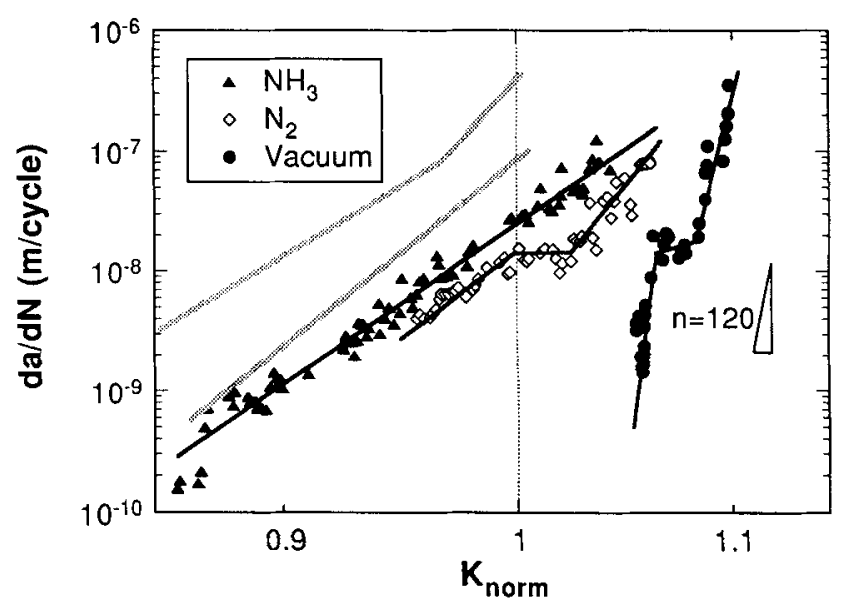

(b)

Fig. 3. (a) Normalized cyclic fatigue in moist environments. (b) Normalized cyclic fatigue in "dry" environments (shaded lines indicate bounds of data in moist environments).

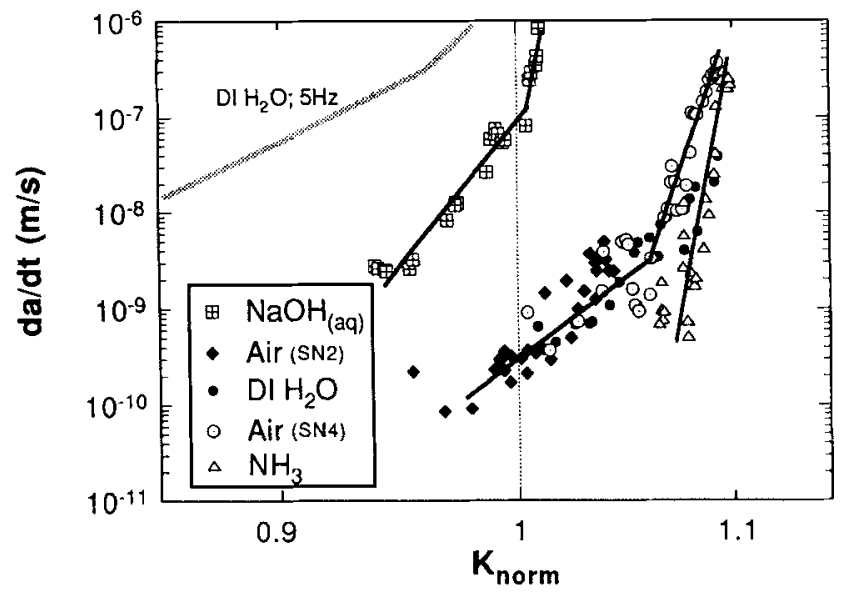

Fig. 4. Influence of environment on static fatigue in $\mathrm{Si}_{3} \mathrm{~N}_{4}$. Cyclic fatigue in $\mathrm{H}_{2} \mathrm{O}$ is shown by thick shaded line for comparison.

systematic differences among these four were difficult to discern. Crack growth rates in $\mathrm{DI} \mathrm{H}_{2} \mathrm{O}$ were at most twice as fast as in moist air, while growth rates in decane appear to be slightly slower than in moist air. The curve measured in aqueous $\mathrm{NaOH}$ lies in the same range of $K_{\text {norm }}$ and $\mathrm{d} a / \mathrm{d} N$, but it appears to have a higher slope than the other data sets. A convincing systematic difference is hard to determine because of the scatter inherent in the data. The best assessment we have is that all the results in moist environments fall in the band bounded by heavy lines in Fig. 3(a), and that increasing the amount of water in the environments produces a small but measurable increase in crack growth rates.

The Paris law exponent found from the slopes of the curves in Fig. 3(a) ranged from about 28 to 41 and had a mean value of 35 , which is typical of values reported for other ceramic materials. ${ }^{16}$ The curves generally show an increase in slope around $K_{\text {nom }}=0.97$. Most of the fatigue curve lies below $K_{\text {norm }}=1$ in these moist environments, and catastrophic failure was observed in several cases if $K_{\text {norm }}$ exceeded about $1.05(\mathrm{~d} a / \mathrm{d} N$ just before failure was about $2 \times 10^{-6} \mathrm{~m} /$ cycle).

(b) "Dry" Environments: Figure 3(b) shows data for cyclic fatigue in the three relatively dry environments, as well as the boundaries of the moist environment data. Compared to fatigue in moist environments, growth rates in anhydrous $\mathrm{NH}_{3}$ were 2 to 5 times slower at the same $K_{\text {norm }}$, while the slope of the curve is not significantly different. Growth rates were some what slower in $\mathrm{N}_{2}$ than in $\mathrm{NH}_{3}$, and a plateau region appears to be developing around $\mathrm{d} a / \mathrm{d} N=1.5 \times 10^{-8} \mathrm{~m} /$ cycle. Below the plateau the slope is about the same as for moist environments, while above the plateau there is a pronounced increase in slope. Note that stable crack growth is occurring well above $K_{\text {norm }}=1$ in these "dry" environments. Indeed, in the vacuum environment the entire range of measurable crack growth lies above $K_{\text {norm }}=1$. A plateau region may exist here at $\mathrm{d} a / \mathrm{d} N \approx 1.5 \times$ $10^{-x} \mathrm{~m} /$ cycle, but the slope of the fatigue curve is about 3 times larger over the whole range of data compared to the moist environments.

\section{(3) Static Fatigue}

Figure 4 summarizes the effect of environment on static fatigue in our materials. Tests were conducted mainly under constant load (increasing $K_{\max }$ due to crack growth) conditions, with some quasi-static loading during the initial stages for the data in moist air and $\mathrm{H}_{2} \mathrm{O}$. The cyclic fatigue curve in $\mathrm{H}_{2} \mathrm{O}$, which was converted to $\mathrm{m} / \mathrm{s}$ for this figure, is also included for comparison. All data shown have been normalized as described in Section III(1). Static fatigue growth rates in moist air and DI $\mathrm{H}_{2} \mathrm{O}$ are seen to be approximately the same, and they are slower by up to 3 or 4 orders of magnitude compared to those in cyclic fatigue at the same $K_{\text {norm. }}$. At high $K_{\text {norm }}$ and da/d t the slope of these curves is about twice that of the cyclic fatigue curve in $\mathrm{H}_{2} \mathrm{O}$, while at low $K_{\text {norm }}$ and $\mathrm{d} a / \mathrm{d} t$ (where we had to perform quasi-static loading) the data appear to run parallel to the cyclic fatigue curve. In $\mathrm{NH}_{3}$, static fatigue growth rates are significantly slower than in air or $\mathrm{H}_{2} \mathrm{O}$, and the slope of the curve is about 4 times that of the cyclic fatigue curve in $\mathrm{H}_{2} \mathrm{O}$. Most of the data for these three environments, which were acquired with the SN2 and SN4 material, lie above $K_{\text {norm }}=1$ and are closest to the cyclic fatigue curve for vacuum. Data obtained in the $\mathrm{NaOH}_{(\mathrm{aq})}$ environment, acquired with the SNI material, show a slightly different behavior. These data lie mainly below $K_{\text {norm }}=$ 1 , are much closer to the cyclic fatigue data for moist environments, and exhibit faster growth rates at a given $K_{\text {norm }}$ compared to the other materials. The close proximity of static and cyclic fatigue curves for $\mathrm{SN} 1$ is similar to results reported by Kishimoto et al. for sintered $\mathrm{Si}_{3} \mathrm{~N}_{4}$ tested in moist air. ${ }^{10-12}$

\section{(4) Block Loading Tests}

Two general types of behavior were seen during block loading tests for any given material and environment, which we illustrate here using data from the $\mathrm{SN} 2$ material tested in moist air. At low values of $K_{\max }$, crack growth essentially arrested when the loading was switched from cyclic to static loading at the same $K_{\text {max }}$, as shown in Fig. 5(a). At higher $K_{\max }$ significant crack growth $(\sim 30 \mu \mathrm{m}$ over $2 \mathrm{~h})$ was observed during the static 


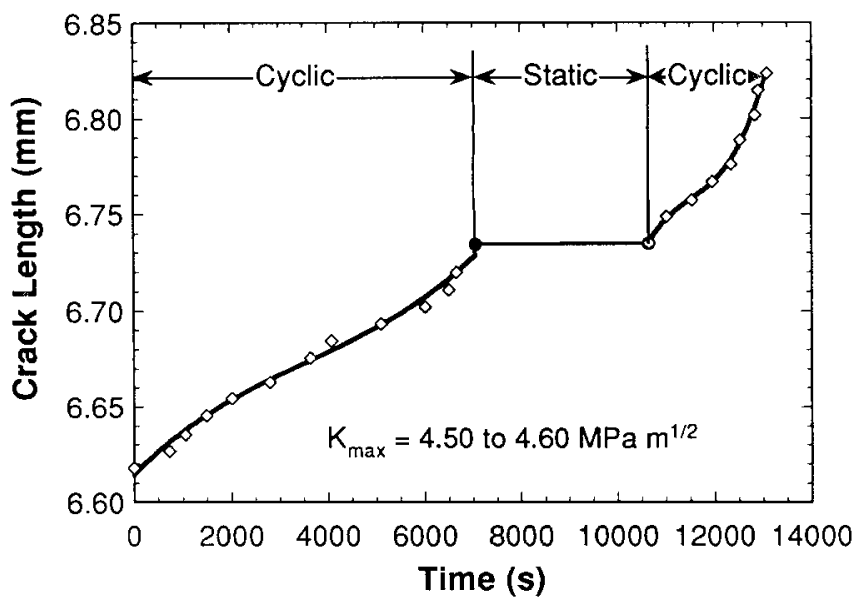

(a)

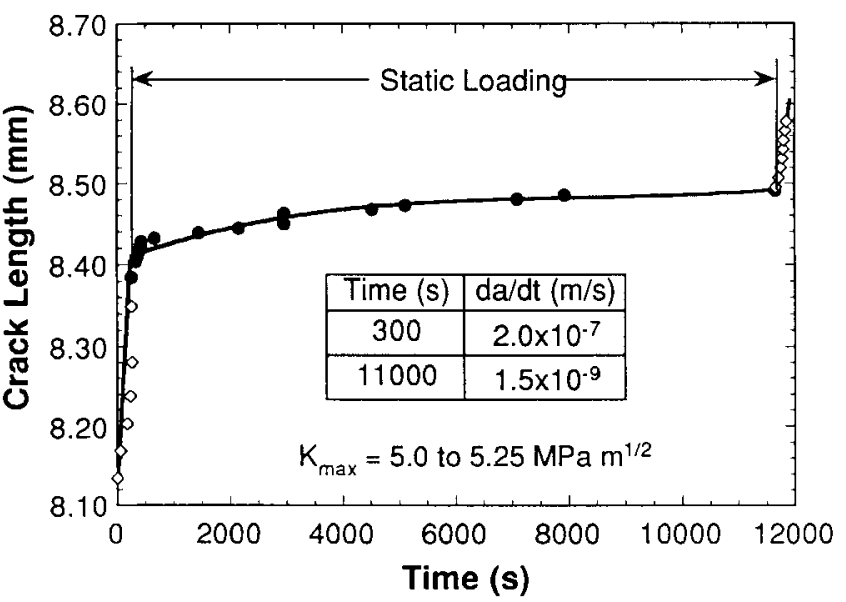

(b)

Fig. 5. Typical behavior during block loading tests: (a) Arrest of crack at lower $K_{\max }$; (b) transient deceleration to a steady-state value at higher $K_{\text {tnax }}$. Data are for SN2 material tested in moist air. $R=0.1$ and $f=5 \mathrm{~Hz}$ for cyclic loading segments.

segment, but growth rates were transient and decreased over time, as shown in Fig. 5(b). This transient growth was seen even under vacuum. Some evidence of delayed acceleration when switching from static back to cyclic loading was also found. In general, these results show that cyclic fatigue can proceed in the absence of static fatigue, and that any contribution from static fatigue is more prevalent at the higher $K_{\max }$ range of cyclic fatigue. The transient behavior also suggests that the $R$-curve influences the static fatigue results, as discussed in Section IV(6).

\section{(5) Fractography}

Figure 6(a) shows the microstructure of the SN1 material, as revealed by etching a fracture surface with molten $\mathrm{NaOH}$ to remove any intergranular glass phase. The material is quite fine-grained, with grain diameters ranging from 0.1 to $0.5 \mu \mathrm{m}$, and grain lengths up to about $1.5 \mu \mathrm{m}$. This fine microstructure is consistent with the relatively low toughness of the SN1 material. ${ }^{31}$ In contrast, the fracture surface produced by cyclic fatigue (in moist air) is shown in Fig. 6(b). Both fracture halves had this appearance, with fracture being mainly intergranular and with large amounts of glass coating the grains. The presence of so many glass-coated grains on both halves indicates that fracture was largely through the glass, and that the intergranular glass was the locus of environmental interaction in the $\mathrm{SN} 1$ material.

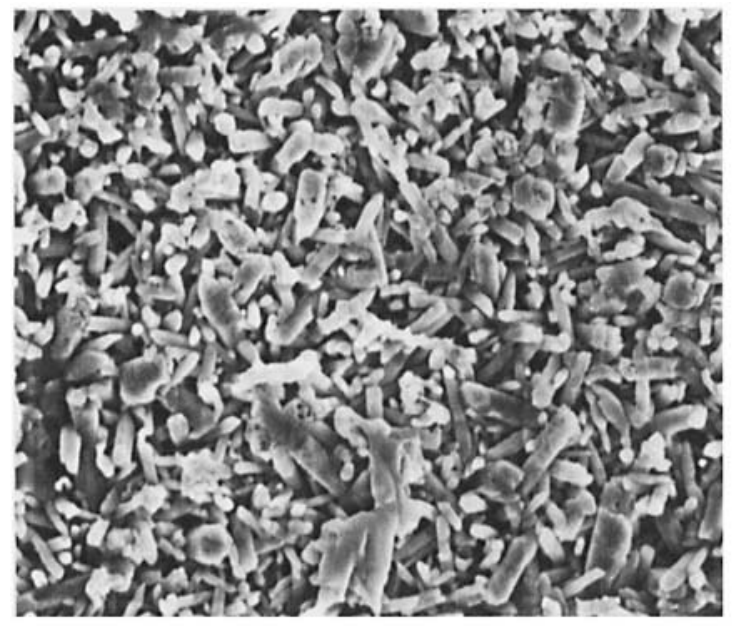

(a)
The microstructures revealed by etching in molten $\mathrm{NaOH}$ for the SN2-4 materials were very similar, and a representative micrograph is shown in Fig. 7(a). A coarser, bimodal microstructure is apparent, with grain diameters ranging from about 0.1 to $1.5 \mu \mathrm{m}$ and grain lengths reaching 4 or $5 \mu \mathrm{m}$. This microstructure is consistent with the relatively high toughness of these materials. ${ }^{31}$ Fracture under cyclic fatigue (in moist air) was again mainly intergranular, as shown by a representative micrograph in Fig. 7(b).

In all our materials, the test environment produced no significant difference in the appearance of the fracture surfaces. Static loading and fast fracture did result in somewhat larger amounts of transgranular fracture compared to cyclic fatigue, but the difference is difficult to quantify. No effect of environment was seen on these bands. Macroscopically, static fatigue and fast fracture produced bands of lighter contrast than cyclic fatigue. This contrast was discernible with the naked eye but was lost at higher magnifications. It was postulated that the contrast was produced by the differing amounts of transgranular fracture in each region and that this would correlate with surface roughness, as found by Fletcher et al. ${ }^{32}$ However, the arithmetic average surface roughness was the same for both light and dark regions $\left(R_{\mathrm{a}}=1.8 \mu \mathrm{m}\right.$, measured using a Sheffield Proficorder Spectre System) so surface roughness does not appear to generate the contrast. Other causes are possible, such

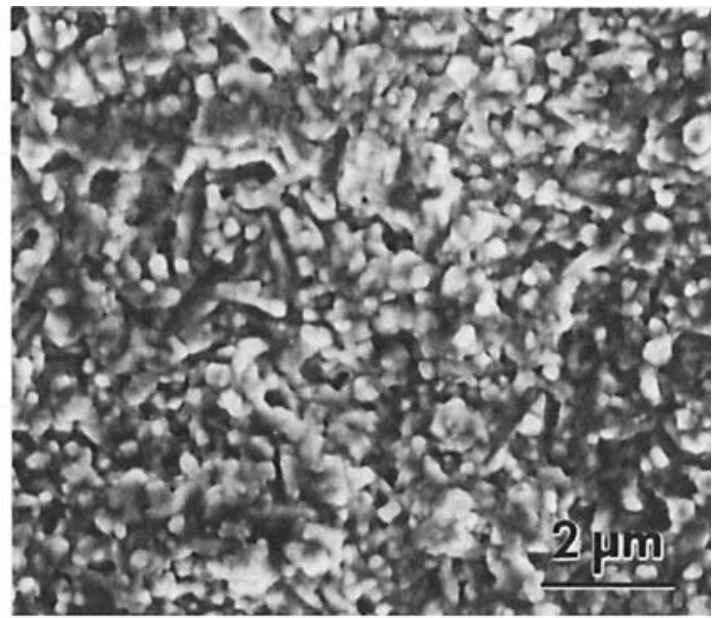

(b)

Fig. 6. Fracture surfaces of $\mathrm{SN} 1$ : (a) etched in molten $\mathrm{NaOH}$ for $15 \mathrm{~s}$ at $318^{\circ} \mathrm{C}$ to reveal underlying grain structure; (b) surface produced by cyclic fatigue. 


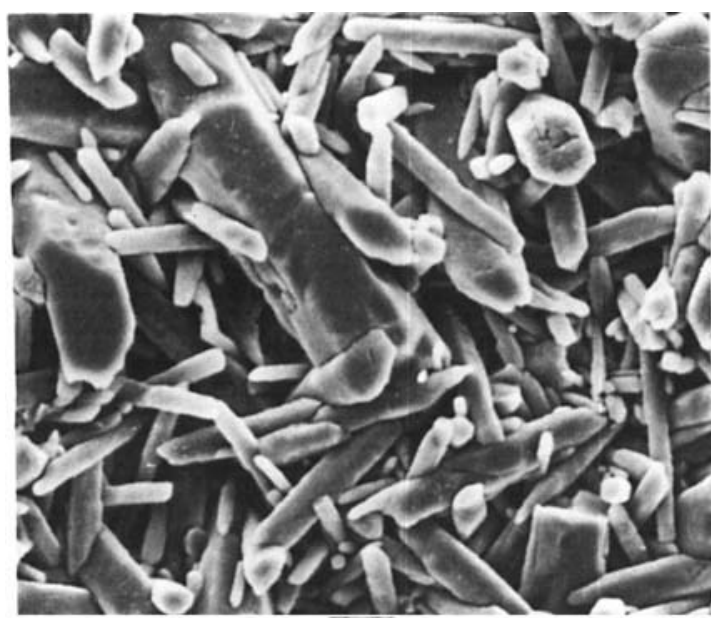

(a)

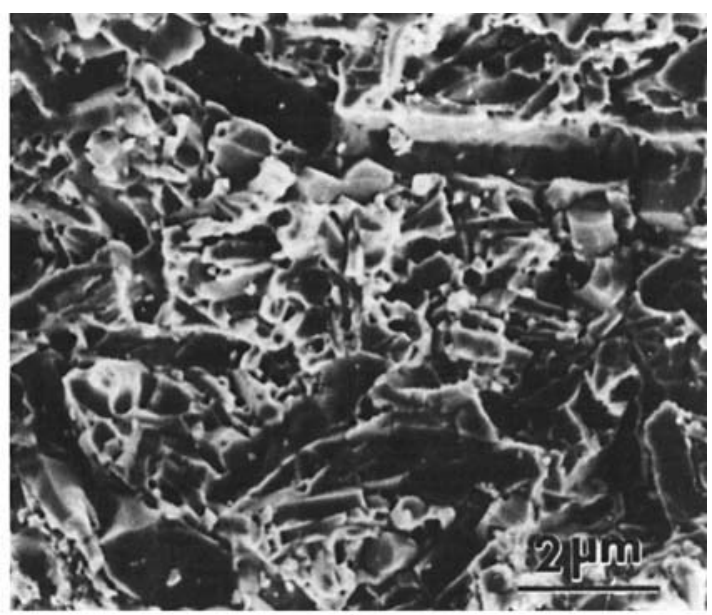

(b)

Fig. 7. Representative microstructure of SN2, SN3, and SN4. Surfaces produced by (a) etching in molten NaOH for $35 \mathrm{~s}$ at $318^{\circ} \mathrm{C}$ to reveal underlying grain structure, (b) cyclic fatigue in moist air (SN3).

as differences in surface reflectivity due to fretting wear or to the presence of more intergranular glass on the cyclic fatigue regions. Further study is needed to resolve this question.

\section{Discussion}

\section{(1) Effects of Moisture}

The materials tested all appear to be most sensitive to the amount of water in the environment. Water is known to chemisorb onto strained bonds in ceramics such as $\mathrm{SiO}_{2}$ and $\mathrm{Al}_{2} \mathrm{O}_{3}$, and this is one mechanism responsible for the occurrence of static fatigue in these materials. ${ }^{18,22,23}$ For our $\mathrm{Si}_{3} \mathrm{~N}_{4}$ materials in cyclic fatigue, the most striking example of this sensitivity is seen under vacuum. When the amount of water is reduced to several parts per billion under vacuum, there is a decrease in cyclic growth rates by more than 3 orders of magnitude compared to the moist air environment.

Water sensitivity is also revealed by the tests conducted in decane and $\mathrm{N}_{2}$. These species are not believed to chemisorb at strained crack tip bonds, but they are expected to have various amounts of $\mathrm{H}_{2} \mathrm{O}$ dissolved in them. ${ }^{18-20}$ The decane is expected to have about $50 \%$ relative humidity due to exposure to room air, which is equivalent to about $120 \mathrm{ppm} \mathrm{H}_{2} \mathrm{O}$ by weight. ${ }^{33} \mathrm{On}$ the other hand, the "dry" $\mathrm{N}_{2}$ is prepurified to about $8 \mathrm{ppm} \mathrm{H}_{2} \mathrm{O}$, which is equivalent to about $0.04 \%$ relative humidity. The difference in crack growth rates, which are about 5 times faster in decane than in $\mathrm{N}_{2}$, thus appears to result from the difference in $\mathrm{H}_{2} \mathrm{O}$ in these environments. (The results in anhydrous $\mathrm{NH}_{3}$ appear to depend on the reactivity of $\mathrm{NH}_{3}$ rather than $\mathrm{H}_{2} \mathrm{O}$, and this is discussed in Section IV(4)). Therefore, the sensitivity of cyclic fatigue to water is quite clear from the data. Although the static fatigue data are not as extensive, they appear to follow the same trends as the cyclic data in terms of environmental sensitivity.

\section{(2) Correlations with Fatigue in Glass}

The moisture sensitivity of our materials is very similar to that seen in $\mathrm{SiO}_{2}$-based glasses under static fatigue. This suggests that the chemisorption reaction aiding crack propagation in static fatigue also operates in cyclic fatigue. Static fatigue in glass is generally divided into three stages, as illustrated in Fig. 8. In stage I, crack velocities are directly proportional to the activity of water (or other reactive species) in the environment, while the slopes for different test humidities are about the same. Stage II is characterized by a plateau region where crack velocities are thought to be limited by the rate of water transport to the crack tip. The onset of this stage depends on the concentration of water and the viscosity of the test media. Stage III lies above the plateau region, and crack velocities again become very sensitive to changes in $K_{\max }$. Here, data for various humidities join onto one line, and crack growth is thought to depend not on water concentration or activity, but on the dielectric properties of the material and the test media. ${ }^{18}$

The data in this study, for both cyclic and static fatigue, closely resemble the three-stage process described above. Most of the data, except for those under vacuum and at higher $K_{\text {norm }}$ in $\mathrm{N}_{2}$, correlate best with stage $\mathrm{I}$. They show a trend of decreasing crack velocity with decreasing water content, and each $\mathrm{d} a / \mathrm{d} t$ vs $K$ curve has a slope much steeper than one would expect for stage II. The data under vacuum have a larger slope and are shifted to a higher $K$-regime, which appears to correspond to stage III in glasses. ${ }^{17,18}$ The strongest indications of stage II plateaus in our data are for cyclic fatigue of SN4 in $\mathrm{N}_{2}$, and perhaps under vacuum. In the other cyclic and static fatigue curves, clear evidence of this stage is difficult to discern. This is not surprising. A review of the static fatigue literature indicates that stage II has been seen in double cantilever beam (DCB)

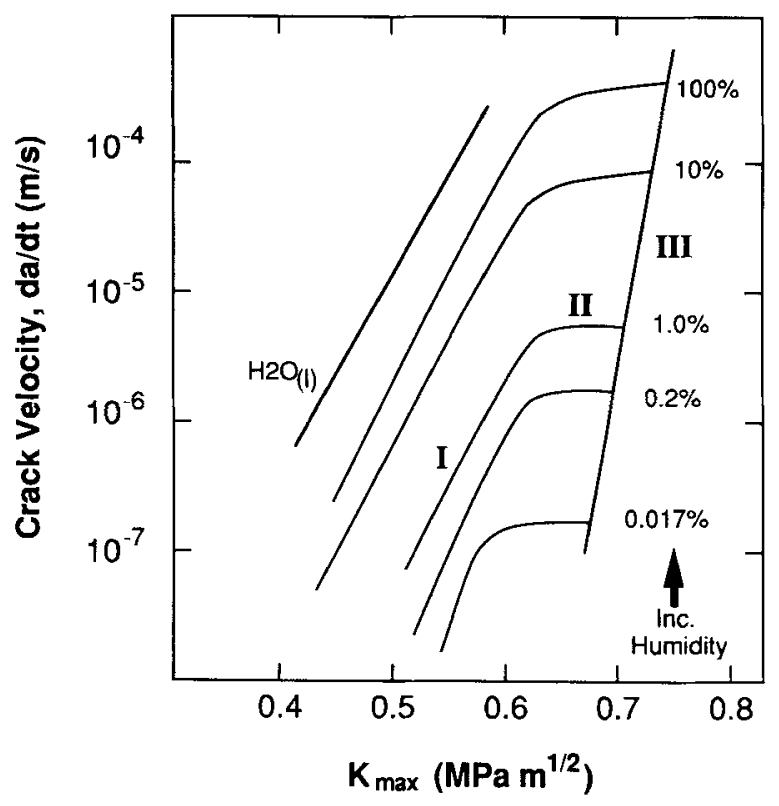

Fig. 8. Effect of relative humidity on static fatigue of soda-lime silicate glass (after Wiederhorn ${ }^{18}$ ). 
specimens of glasses, $\mathrm{ZrO}_{2}$, and $\mathrm{Al}_{2} \mathrm{O}_{3}$ in moist environments, but usually at growth rates well above $10^{-6} \mathrm{~m} / \mathrm{s}$. Since crack instability in our CT specimens at high $\mathrm{d} a / \mathrm{d} t$ prevents us from sampling this range, stage Il would only be expected to appear in very low humidity environments, such as $\mathrm{N}_{2}$. Thus, we conclude that most of our cyclic and static data correspond best with a stage I type process. The two regions of different slope in some of the static fatigue curves are more consistent with mechanical rather than environmental effects, as will be discussed in Section IV(6).

The most notable difference between our results and those for glass is that our data do not show the direct proportionality to water activity found by Wiederhom et al..$^{17,18}$ For instance, growth rates in moist environments are only 8 to 15 times faster than those in $\mathrm{N}_{2}$, while one would expect them to be about 500 to 1250 times faster. This discrepancy could result from a deviation from first-order reaction kinetics, as noted in some tests by Wiederhorn ${ }^{18}$ and Freiman, ${ }^{20}$ or perhaps from the polycrystalline nature of our materials. In all other aspects, however, our results in both cyclic and static fatigue mirror those for static fatigue of glass. This indicates that chemisorption at the crack tip is occurring under both types of loading in our materials.

\section{(3) Effects of $\mathrm{pH}$}

The apparent lack of a pH sensitivity is analogous to that seen in soda-lime silicates, in which a pH between about 2 and 14 has no discernible effect on fracture stress ${ }^{34}$ or on $\mathrm{d} a / \mathrm{d} t .^{24}$ This observation may be attributed to the nature of the grain boundary glass in our materials. Our intergranular phase is an yttrium-containing oxynitride glass which, along with sodalime silicates, is known to be a "durable" or corrosion-resistant material. In particular, Wusirika ${ }^{35}$ has shown that yttrium-containing glasses, whether silicates or oxynitrides, are very resistant to corrosion by concentrated $\mathrm{NaOH}$ up to about $100^{\circ} \mathrm{C}$. Therefore, the insensitivity to $\mathrm{pH}$ observed in $\mathrm{SNl}$ is not surprising.

\section{(4) Other Reactive Species $\left(\mathrm{NH}_{3}\right)$}

Michalske et al..$^{22.23}$ have shown that for vitreous $\mathrm{SiO}_{2}$ and sapphire under static fatigue, "dry" $\mathrm{NH}_{3}$, with a relative humidity of $1-5 \%$, will produce crack growth rates equal to those produced by $\mathrm{H}_{2} \mathrm{O}$. They concluded that $\mathrm{NH}_{3}$, like $\mathrm{H}_{2} \mathrm{O}$, chemisorbs at strained $\mathrm{Si}-\mathrm{O}$ or $\mathrm{Al}-\mathrm{O}$ bonds at the crack tip. Molecular orbital (MO) calculations by several groups ${ }^{22.23,36}$ have shown that a strained $\mathrm{Si}-\mathrm{O}$ bond constitutes an acid-base pair which can react with environmental species that have a Lewis base site adjacent to a proton donor site (such as $\mathrm{H}_{2} \mathrm{O}$ and $\mathrm{NH}_{3}$ ). Freiman et al. ${ }^{37}$ also found $\mathrm{NH}_{3}$ to be corrosive to soda-lime silicate glass, though growth rates were up to 10 times slower than in $\mathrm{H}_{2} \mathrm{O}$ for this type of glass. The difference between vitreous silica and soda-lime silicates was believed to result from the effect of modifying cations on the reactivity of Si-O bonds and by the presence of nonbridging oxygens in the glass network.

The effect of $\mathrm{NH}_{3}$ on our materials appears similar to that seen in soda-lime silicates. In both static and cyclic fatigue, growth rates in $\mathrm{NH}_{3}$ were at least 10 times slower than in $\mathrm{H}_{2} \mathrm{O}$. Assuming that the $\mathrm{NH}_{3}$ is at least as dry as the $\mathrm{N}_{2}$ environment, ammonia appears to have only a small effect on crack growth rates compared to $\mathrm{H}_{2} \mathrm{O}$. The presence of $\mathrm{Y}^{3+}$ in our intergranular glass phase may account for this. ${ }^{37}$ However, the presence of nitrogen in our glass may also be responsible, since we may speculate that $\mathrm{Si}-\mathrm{N}$ or $\mathrm{O}-\mathrm{Si}-\mathrm{N}$ groups may be less reactive, at a given strain, than $\mathrm{Si}-\mathrm{O}$ bonds.

\section{(5) Site of Environmental Interactions}

The environmental sensitivities discussed above, coupled with the large amounts of glass on the fracture surfaces (especially on the SN1 material), suggest that the site of the chemisorption reaction is at the intergranular glass phase in our materials. However, a definitive resolution to this issue is not trivial. Although grain boundaries in liquid-phase-sintered $\mathrm{Si}_{3} \mathrm{~N}_{4}$ are always coated with an amorphous glass, ${ }^{38}$ the literature does not indicate whether cracks propagate through this glass or along the glass-grain interface. Our own ESCA studies were inconclusive because of the mixed inter- and intragranular fracture of our materials and because the escape depth of X-ray photoelectrons can be up to $50 \AA$ while the glass layer may often have a thickness of only 10 to $20 \AA .{ }^{36}$ In addition, Jo et al. ${ }^{39}$ have found that both $\mathrm{O}_{2}$ and $\mathrm{H}_{2} \mathrm{O}$ will quickly and readily chemisorb onto pure, unstrained $\mathrm{Si}_{3} \mathrm{~N}_{4}$, converting the surface to an $\mathrm{SiO}$ - or $\mathrm{SiOH}$-rich layer. Finally, Sato et al ${ }^{40}$ have found that the matrix $\mathrm{Si}_{3} \mathrm{~N}_{4}$ is preferentially attacked under hydrothermal conditions when the grain boundary phase contains $\mathrm{Y}_{2} \mathrm{O}_{3}$ and $\mathrm{Al}_{2} \mathrm{O}_{3}$, as do our materials. Therefore, although we have some indications that chemisorption happens mainly with the intergranular glass, an interaction with the $\mathrm{Si}_{3} \mathrm{~N}_{4}$ matrix cannot be unequivocally ruled out as the origin of the observed environmental sensitivities.

\section{(6) Influence of the R-Curve}

For nontransformable ceramics such as $\mathrm{Si}_{3} \mathrm{~N}_{4}$ and $\mathrm{Al}_{2} \mathrm{O}_{3}$, an $R$-curve results from the accumulation of frictional bridges in the crack wake. ${ }^{31,41}$ These bridges shield the crack tip from the applied far field stresses, so that

$$
K_{\text {tip }}=K_{\text {max }}-K_{\text {sh }}
$$

Here $K_{\text {tip }}$ is the stress intensity at the crack tip (the actual driving force for crack growth), and $K_{\mathrm{sh}}$ is the magnitude of shielding. ${ }^{42}$ A crack will grow critically when $K_{\text {tip }}=K_{0}$, the intrinsic toughness of the material, or subcritically when $K_{\text {tip }} \leq K_{0}$, as in static fatigue. Under monotonically increasing loads, $K_{\mathrm{sh}}$ usually increases as the crack grows, producing an $R$-curve such as that shown in Fig. 9 for the SN3 material. The $R$-curve shown is typical of those reported in the literature. ${ }^{29,43,44}$

The $R$-curves of SN2-4 should be similar, since they have very similar microstructures, while the $R$-curve for the finegrained SN1 should be quite different. Indeed, Vekinis et al. ${ }^{43}$ have shown for $\mathrm{Al}_{2} \mathrm{O}_{3}$ that increasing the grain size leads to a steeper $R$-curve with a higher plateau toughness, $K_{x}$, and that the difference between $K_{0}$ and $K_{\infty}$ also increases with grain size. Since static fatigue tests are similar to $R$-curve tests $\left(K_{\max }\right.$ is always increasing, and there is no load oscillation), we would expect to see an influence of the $R$-curve in our static data if $K_{\text {sh }}$ is not saturated at the start of the static tests. We believe that we do indeed see evidence of this. The static fatigue data for moist air and $\mathrm{H}_{2} \mathrm{O}$ (Fig. 4) are unlikely to correspond to stage II and stage III static fatigue, as discussed in Section IV(2). However, the region of lower slope, at low $K_{\text {norm }}$, is possibly a region where $K_{\mathrm{sh}}$ is increasing, so that a large change in $K_{\max }$ is needed to produce a small change in $K_{\text {tip }}$ and thus in $\mathrm{d} a / \mathrm{d} t$. The region of higher slope appears to be a region where $K_{\mathrm{sh}}$ is saturated. In addition, the failure of the static fatigue data for the $\mathrm{SN} 1$ material to normalize onto a universal curve may be explained if the increase in $K_{\mathrm{sh}}$ is greater for SN2-4 than for SN1, as expected

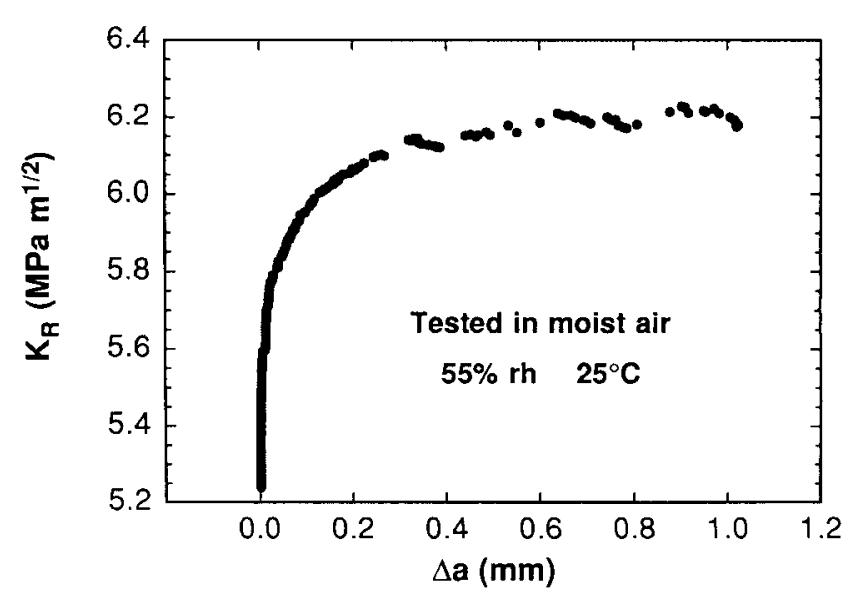

Fig. 9. $R$-curve measured for SN3 material. 
from the results of Vekinis et al. These conclusions are rather speculative at this time, but are included to underline the importance of considering $R$-curve behavior in static fatigue tests.

\section{(7) Mechanism of Cyclic Fatigue}

Despite the analogies drawn so far between cyclic fatigue in $\mathrm{Si}_{3} \mathrm{~N}_{4}$ and static fatigue in glass, it is clear that cyclic loading itself is capable of producing crack growth even in the absence of environmentally assisted static fatigue. This is seen most clearly in the vacuum data, as cyclic fatigue under vacuum (SN4 material) is faster than static fatigue in reactive environments. Block loading test results, such as in Fig. 5, show that crack growth can be dormant under static loads in regimes where growth readily occurs under cyclic loads, even under vacuum. These observations confirm that cyclic fatigue is not simply a manifestation of static fatigue, but a distinctly different phenomenon.

It has been suggested that cyclic fatigue causes mechanical degradation of crack wake shielding, resulting in a higher local driving force for crack growth compared to static fatigue. ${ }^{45}$ Equation (2) indicates that if $K_{\mathrm{sh}}$ is lower in cyclic than in static fatigue, for a given applied $K_{\max }$, then $K_{\text {tip }}$ will be larger in cyclic fatigue, and therefore growth rates will be faster. The effect of a degraded $K_{\mathrm{sh}}$ will be enhanced when, as we have documented in this work, environmental interactions at the crack tip facilitate fracture during cyclic fatigue. Thus, mechanical degradation of crack wake shielding will result in higher $\mathrm{d} a / \mathrm{d} t$ whether cyclic fatigue proceeds by critical or subcritical fracture.

Several of our results support the conclusion that cyclic fatigue degrades $K_{\text {sh }}$. If, as discussed above, $K_{\text {sh }}$ does increase during static fatigue, this implies that $K_{\mathrm{sh}}$ was prevented from reaching saturation during previous cyclic testing. Static tests were always immediately preceded by cyclic fatigue tests, except for the one in $\mathrm{NH}_{3}$, which followed a static fatigue test in air and shows no region which we associate with increasing $K_{\mathrm{sh}}$. Thus, we infer that the cyclic fatigue prior to the air and $\mathrm{H}_{2} \mathrm{O}$ tests degraded crack wake shielding. This also indicates that the load history immediately preceding the static fatigue test, rather than the total load history, has the largest effect on test results.

More convincing, however, is that the transient decay of $\mathrm{d} a / \mathrm{d} t$ was seen in many static segments during block loading tests. This suggests a repetitive process of shielding degradation during cyclic segments followed by shielding accumulation during static segments. The transient decay most likely occurs because, during static fatigue, $K_{\mathrm{sh}}$ is following the rising portion of the $R$-curve and is likely to increase much faster than $K_{\max }$ as the crack grows. This reduces the local driving force $\left(K_{\text {tip }}\right)$ and, consequently, $\mathrm{d} a / \mathrm{d} t$. We note that initially $\mathrm{d} a / \mathrm{d} t$ in the static segment is slightly less than in the cyclic segment, and that it rapidly decays by 2 or more orders of magnitude (cf. Fig. 5(b)). When cyclic fatigue is resumed, the crack quickly attains a fast growth rate. In the next static segment, the initial $\mathrm{d} a / \mathrm{d} t$ is again close to, but slightly less than, that in cyclic fatigue before the transient decay is again seen. Thus, $K_{\text {tip }}$ is apparently higher at the start of the second static segment compared to the end of the first one. Therefore, the effect of cyclic loading is to degrade crack wake shielding, thus allowing a higher local driving force and faster crack propagation at the same applied $K_{\max }$ compared to static fatigue.

\section{Conclusions}

(1) Cyclic fatigue in $\beta-\mathrm{Si}_{3} \mathrm{~N}_{4}$ is a mechanical process that can occur in the absence of measurable static fatigue, even under vacuum. However, cyclic fatigue is also sensitive to the environment and displays the same trends with environment as static fatigue. This indicates that a chemisorption process occurring at the crack tip influences crack growth for both types of fatigue.

(2) The interaction with water is often the strongest determinant of environmental sensitivity in both cyclic and static fatigue of our materials. Crack propagation is sensitive to water activity at lower growth rates, similar to stage $I$ in glasses. In more inert environments a stage II-type plateau region is observed, followed by a very steep $K$-dependence at higher stress intensities, similar to stage III in glasses.

(3) The sensitivity of our materials to $\mathrm{pH}$ and to $\mathrm{NH}_{3}$ is low, similar to behavior seen in soda-lime silicate glasses. This is most likely a result of good chemical durability of the $\mathrm{Y}$-Si-Al-O-N intergranular glass.

(4) Cyclic fatigue degrades crack wake shielding in $\mathrm{Si}_{3} \mathrm{~N}_{4}$, while static fatigue may increase $K_{\mathrm{sh}}$ or lead to shielding saturation. This results in a higher local driving force under cyclic fatigue for a given applied $K_{\max }$ and thus faster crack propagation compared to static fatigue. This also accounts for the transient deceleration observed in block loading tests.

\section{References}

R. H. Dauskardt, W. Yu, and R. O. Ritchie, "Fatigue Crack Propagation in Transformation-Toughened Zirconia Ceramic," J. Am. Ceram. Soc., 70 [10] C-248-C-252 (1987).

${ }^{2}$ R. H. Dauskardt, D. B. Marshall, and R. O. Ritchie, "Cyclic Fatigue-Crack Propagation in MgO-PSZ Ceramics," J. Am. Ceram. Soc., 73 [4] 893-903 $(1990)$.

${ }^{3}$ S. Y. Liu and I-W. Chen, "Fatigue of Yttria-Stabilized Zirconia: II, Crack Propagation, Fatigue Striations, and Short Crack Behavior," J. Am. Ceram. Soc., 74 [6] $1206-18$ (1991).

${ }^{4}$ J. F. Tsai, C. S. Yu, and D. K. Shetty, "Fatigue Crack Propagation in CeriaPartially-Stabilized Zirconia (Ce-TZP)-Alumina Composites," J. Am. Ceram. Soc, 73 [10] 2992-3001 (1990).

5P. F. Becher, "Subcritical Crack Growth in Partially Stabilized $\mathrm{ZrO}_{2}(\mathrm{MgO})$," J. Mater. Sci., 21, 297-300 (1986).

${ }^{6} \mathrm{~L}$. Ewart and S. Suresh, "Crack Propagation in Ceramics Under Cyclic Loads," J. Mater. Sci., 22, 1173-92 (1987).

'S. Lathabai, J. Rodel, and B. Lawn, "Cyclic Fatigue from Frictional Degradation at Bridging Grains in Alumina," J. Am. Ceram. Soc., 74 [6] 1340 (1991).

${ }^{8}$ M. Okazaki, A. J. McEvily, and T. Tanaka, "On Fatigue Crack Growth in Silicon Nitride," Metall. Trans. A, 22A [6] 1425-34 (1991).

${ }^{9}$ T. Kawakubo, N. Okabe, and T. Mori, "Static and Cyclic Fatigue Behavior in Ceramics," Proc. Int. Conf. Fatigue Fatigue Thresh., 4th, 2, 717-26 (1990).

"H. Kishimoto, A. Ueno, and H. Kawamoto, "Crack Propagation Behavior of $\mathrm{Si}_{3} \mathrm{~N}_{4}$ Under Cyclic Loads-Influence of Difference in Materials," Proc. Int. Conf. Fatigue Fatigue Thresh., 4th, 2, 727-32 (1990).

"A. Ueno, H. Kishimoto, H. Kawamoto, and M. Asakura, "Crack Propagation Behavior of Sintered Silicon Nitride Under Cyclic Load of High Stress Ratio and High Frequency," Proc. Int. Conf. Fatigue Fatigue Thresh., 4th, 2, 733-38 (1990).

${ }^{12} \mathrm{H}$. Kishimoto, A. Ueno, and H. Kawamoto, "Crack Propagation Behavior of Sintered Silicon Nitride Under Cyclic Loads," Proc. MRS Int. Meet. Adv. Mater., Ist, 5, 531-36 (1989).

${ }^{13}$ M. Masuda, T. Soma, and M. Matsui, "Cyclic Fatigue Behavior of $\mathrm{Si}_{3} \mathrm{~N}_{4}$ Ceramics," J. Eur. Ceram. Soc., 6, 253--58 (1990).

${ }^{14} \mathrm{~S}$. Horibe, "Fatigue of Silicon Nitride Ceramics Under Cyclic Loading," J. Eur. Ceram. Soc., 6, 89-95 (1990).

${ }^{15}$ S. Horibe, "Cyclic Farigue Damage and Microstructure of Ceramic Materials," Proc. Int. Conf. Fatigue Fatigue Thresh., 4th, 2, 753-58 (1990).

${ }^{16}$ R. H. Dauskardt, M. R. James, J. R. Porter, and R. O. Ritchie, "Cyclic Fatigue-Crack Growth in a Silicon Carbide Whisker-Reinforced Alumina Ceramic Composite: Long and Small-Crack Behavior," J. Am. Ceram. Soc., 75 [4] 759-71 (1992).

17S. M. Wiederhorn, "Influence of Water Vapor on Crack Propagation in Soda-Lime Glass," J. Am. Ceram. Soc., 50 [8] 407-14 (1967).

${ }^{8}$ S. M. Wiederhorn, S. W. Freiman, E. R. Fuller, Jr., and C. J. Simmons, "Effects of Water and Other Dielectrics on Crack Growth," J. Mater. Sci., 17, $3460-78$ (1982).

${ }^{19} \mathrm{~S}$. W. Freiman, "Effect of Straight-Chain Alkanes on Crack Propagation in Glass," J. Am. Ceram. Soc., 58 [7-8] 339-40 (1975).

${ }^{20} \mathrm{~S}$. W. Freiman, "Effect of Alcohols on Crack Propagation in Glass," I. Am Ceram. Soc., 57 [8] 350-53 (1974).

${ }^{2} \mathrm{~S}$. W. Freiman, "Temperature Dependence of Crack Propagation in Glass in Alcohols," J. Am. Ceram. Soc., 58 [7-8] 340-41 (1975).

${ }^{22}$ T. A. Michalske and S. W. Freiman, "A Molecular Mechanism for Stress Corrosion in Vitreous Silica," J. Am. Ceram. Soc., 66 [4] 284-88 (1983).

${ }^{23}$ T. A. Michalske and B. C. Bunker, "Slow Fracture Model Based on Strained Silicate Structures," J. Appl. Phys., 56 [10] 2686-93 (1984).

${ }^{24}$ C. J. Simmons and S. W. Freiman, "Effect of Corrosion Processes on Subcritical Crack Growth in Glass," J. Am. Ceram. Soc., 64 [11] 683-86 (1981).

${ }^{25}$ S. M. Wiederhorn, H. Johnson, A. M. Diness, and A. H. Heuer, "Fracture of Glass in Vacuum,"J. Am. Ceram. Soc., 57 [8] 336-41 (1974).

${ }^{26} \mathrm{G}$. Leng-Ward and M. H. Lewis, "Crystallization in Y-Si-Al-O-N Glasses," Mater. Sci. Eng., 71, 101-11 (1985).

${ }^{27}$ G. S. White, S. W. Freiman, S. M. Wiederhorn, and T. D. Coyle, "Effects of Counterions on Crack Growth in Vitreous Silica," J. Am. Ceram. Soc., 70 [12] $891-95$ (1987). 
${ }^{2 *} \mathrm{G}$. Sines, "Rationalized Crack Growth and Time-to-Fracture of Brittle Mate rials," J. Am. Ceram. Soc., 59 [7-8] 370-71 (1976).

${ }^{29}$ R. H. Dauskardt, D. B. Marshall, and R. O. Ritchie, "Cyclic Fatigue Crack. Propagation in Magnesia-Partially-Stabilized Zirconia Ceramics," J. Am. Ceram. Soc., 73 [4] 893-903 (1990).

${ }^{30}$ M. Okazaki, A. J. McEvily, and T. Tanaka, "On the Mechanism of Fatigue Crack Growth in Silicon Nitride," Metall. Trans. A, 22A [6] 1425-34 (1991).

${ }^{3}$ P. R. Becher, "Microstructural Design of Toughened Ceramics," J.Am. Ceram. Soc., 74 [2] 255-69 (1991).

${ }^{32}$ T. D. Fletcher, J. J. Petrovic, and J. E. Hack, "Quantitative Fractography of $\mathrm{SiC}$ Whisker-Si ${ }_{3} \mathrm{~N}_{4}$ Matrix Composites," J. Mater. Sci., 26, 4491-98 (1991).

${ }^{33}$ P. Schatzberg, "Solubilities of Water in Several Normal Alkanes from $\mathrm{C}_{7}$ to

$C_{10}, " J$. Phys. Chem., 67 [4] 776-79 (1963)

${ }^{34}$ R. Adams and P. W. McMillan, "Review: Static Fatigue in Glass," J. Mater. Sci., 12, 643-57 (1977).

${ }^{35}$ R. Wusirika, "Alkali Durability of Oxynitride Glass Fibers," J. Am. Ceram. Soc, 74 [2] 454-56 (1991)

${ }^{36}$ W. Wong-Ng, G. S. White, and S. W. Freiman, "Application of Molecular Orbital Calculations to Fracture Mechanics: Effect of Applied Strain on Charge Distribution in Silica," J. Am. Ceram. Soc., 75 [11] 3097-102 (1992).

${ }^{37}$ S. W. Freiman, G. S. White, and E. R. Fuller, Jr., "Environmentally Enhanced Crack Growth in Soda-Lime Glass," J. Am. Ceram. Soc., 68 [3] 10812 (1985).
${ }^{38} \mathrm{H}$. J. Kleebe, "SiC and $\mathrm{Si}_{3} \mathrm{~N}_{4}$ Materials with Improved Fracture Resistance," J. Eur. Ceram. Soc, 10, 151-59 (1992).

${ }^{39}$ Y. - S. Jo, J. A. Schultz, S. Tachi, S. Contarini, and J. W. Rabalais, "Surface Stoichiometry, Structure, and Chemisorption on Silicon Nitride Studied by Direct Recoiling, X-Ray Photoelectron Spectroscopy, and Auger Electron Spectroscopy," J. Appl. Phys., 60 [7] 2564-72 (1986).

${ }^{40}$ T. Sato, T. Murakami, T. Endo, M. Shimada, K. Komeya, T. Kameda, and M. Komatsu, "Corrosion of Silicon Nitride Ceramics Under Hydrothermal Conditions,"J. Mater. Sci., 26, 1749-54 (1991).

${ }^{41}$ P. L. Swanson, C. J. Fairbanks, B. R. Lawn, Y.-W. Mai, and B. J. Hockey, "Crack-Interface Grain Bridging as a Fracture Resistance Mechanism in Ceramics: I, Experimental Study on Alumina," J. Am. Ceram. Soc., 70 [4] 279-89 (1987).

${ }^{42}$ Y.-W. Mai and B. R. Lawn, "Crack-Interface Grain Bridging as a Fracture Resistance Mechanism in Ceramics: II, Theoretical Fracture Mechanics Model," I. Am. Ceram. Soc., 70 [4] 289-94 (1987).

${ }^{43} \mathrm{G}$. Vekinis, M. F. Ashby, and P. W. R. Beaumont, " $R$-Curve Behaviour of $\mathrm{Al}_{2} \mathrm{O}_{3}$ Ceramics," Acta Metall Mater., 38 [6] 115I-62 (1990).

${ }^{44} \mathrm{C}$.-W. Li and J. Yamanis, "Super-Tough Silicon Nitride with $R$-Curve Behavior," Ceram. Eng. Sci. Proc., 10 [7-8] 632-45 (1989).

${ }^{45}$ S. Lathabai, J. Rodel, and B. Lawn, "Cyclic Fatigue from Frictional Degradation at Bridging Grains in Alumina," J. Am. Ceram. Soc, 74 [6] 1340 (1991). 